\title{
DOUTRINA
}

\section{A Desapropriação no Regime das Águas}

\author{
JAIR TOVAR
}

\section{APRECIAÇÃO DO FUNDAMENTO DA DESAPROPRIAÇÃO}

A

desapropriação constitui excepcional limitação do direito de propriedade, hoje utilizada por todos os povos cultos, com fundamento no interêsse coletivo. (1)

E' invocado comumente para sua caracterização o conceito fundamental, que the deu LAURENT: "O interêsse particular não cede diante do geral. O proprietário, mais do que de um interêsse, é titular de um direito, sôbre o qual um interêsse, ainda que geral, não pode nunca prevalecer. Mas a sociedáde, como corolário dos deveres, que se lhe incumbem, possui também direitos mais poderosos, mais imperiosos que quaisquer outros e diante dos quais dévem curvar-se os particulares". (2)

O vigente texto constitucional (3) refere-se a três ordens de casos, que podem permitir êsse direito:

a) a necessidade pública;

b) a utilidade pública;

c) o interêsse social.

A necessidade pública compreende hipóteses denunciadoras de maior gravidade e exigência do que as de utilidade pública ou interêsse social; mas em qualquer delas, para que se permitisse a execução da desapropriação, fazia-se necessária a precedência da integração dos seguintes elementos:

a) verificação da necessidade, utilidade pública ou interêsse social sôbre o objeto da desapropriação, que poderiam ser sujeitos à averiguação judicial;

(1) Para CLóvis Beviláqua "o fundamento da desapropriação é a preponderância do interêsse público sôbre o privado, quando os dois seacham em colisão" - Cod. Civ. vol. $30^{\circ}$ obs. 2 ao art. 590 . MeUCCI - Ist. di Dir. Amm., pág. 548, 6.a ed., vê za desapropriação uma conciliação dos dois direitos - o público e o privado - ou seja uma condição do próprio organismo geral do Direito.

(2) Laurent - Droit Civil, vol. VI, n. ${ }^{\circ} 132$.

(3) E' o seguinte o teor do texto constitucional, constante do artigo 141, \& 16: " $\mathrm{E}$ ' garantido o direito de propriedade, salvo o caso de desapropriação por necessidade ou utılidade pública, ou por interêsse social, mediante prévia e justa indenização em dinheiro".

As anteriores Constituiçōes brasileiras referiram-se ao instituto nos seguintes artigos: a de 1824 , no art. 179 , \& 22 ; a de 1891 , no art. $72, \$ 17$ : a de 1934 , no artigo $113 \mathrm{n} .^{\circ} 17$. 
b) pagamento ou depósito, prévios, referente ao valor do objeto.

KUI BARBOSA, ao apreciar aquela primeira condição, desdobrou-a em duas exigências: $10^{\circ}$ ) - que a emprêsa, obra, ou trabalho ao qual se destina a desapropriação seja de pública utilidade; $2 .^{\circ}$ ) — que a desapropriação de cada um dos bens desapropriados seja indispensável à execução do cometimento ou melhoramento, cuja pública utilidade se reconhecer. (4)

E com aquela clareza solar, que é típica na argumentação do consagrado jurista: Como se vê, a necessidade com que aqui se ocupam os autores, não é a da obra projetada em relação à utilidade pública, senão a do prédio que se quer desapropriar em relação à obra projetada. Depois de exigir que a obra seja conveniente ou útil ao bem público, exige-se, outrossim, que o imóvel, cuja desapropriação se determina, seja "imprescindível"' ̀̀ obra. Săo duas questões sucessivas e diversas. Admitindo que a utilidade pública exija a obra, em seguida se inquire se a obra exige êsse prédio, êsse imóvei, essa desapropriação." (5)

E' de uma nitidez absoluta a fixação que o mestre faz, no tocante a essa exigência, na forma do direito dominante em seu tempo.

Entretanto, a lei atual sôbre desapropriação retirou do Poder Judiciário a faculdade de apreciação da necessidade ou utilidade, e por conseguinte também do interêsse social, estabelecendo uma presunção de direito no simples fato de o Executivo fundamentar o seu ato em qualquer dos aludidos motivos constitucionais.

\section{A DESAPROPRIAÇÃO NO CÓDIGO DE ÁGUAS}

O Código de Águas, no seu artigo 32, prevê a desapropriação no domínio đas águas com referência:

a) às águas públicas de uso comum ou patrimoniais;

b) às águas comuns e às particulares e respectivos álveos e margens. (7)

Não agrada na exposição da sua substância o teor do dispositivo e merece que the façamos certas observações.

Nada a dizer quanto ao exercício da faculdade constitucional no atinente às águas patrimoniais ou dominiais em geral .

O poder público possui os bens dessa espécie com a faculdade de livre disposiçäo, como se fôra qualquer particular em relação aos seus, que estiverem livres de gravames especiais.

Já não acontece o mesmo, em princípio, com os bens públicos de uso comum, pois entram na classe dos bens inalienáveis, por sua natureza; e

(4) Comentários à Const. Federal Brasileira, col. por Homero PIRES, vol. V, pág. 418.

(5) Idem, idem.

(6) Decreto-lei n.o 1.283 , de 18-5-1939, art. $2 .^{\circ}$.

(7) Êsse dispositivo do Código de Águas está em consonância com ○ \& $2 .^{\circ}$ do artigo $2 .^{\circ}$ do Decreto-lei n. 3365 , de 21-6-1941. 
daí a necessidade da prévia mudança de destinação para dominicais daqueles considerados de uso comum.

A seu respeito, desta forma pronunciou-se o codificador civilista, cotejando-os com os bens de uso especial e os dominicais:

"Os primeiros são os que pertencem a todos (res communis omnium). O proprietário dêsses bens é a coletividade, o povo. À administração pública estão confiadas a sua guarda e gestão. Podem utilizar-se dêles tôdas as pessoas, respeitadas as leis e regulamentos. Os segundos são propriedade da União, do Estado e dos Municípios, porém, aplicados a determinada ordem de serviços públicos. Os terceiros são patrimoniais. Sôbre êles a União, o Estado ou o Município exerce poderes de proprietário, segundo os preceitos do direito constitucional e administrativo. (8)

Conquanto dúvidas tivessem ocorrido a respeito (9) no campo da desapropriação, todos os bens se equiparam, no sentido de ser possibilitada a faculdade do poder público, não havendo restrições à expropriação dos bens públicos com fundamento na sua natureza. (10)

De tal modo, para que se compreenda essa faculdade de desapropriação conferida à União em relação aos mesmos bens pertencentes aos Estados e aos Municípios, e ao Estado em relação aos bens dos municípios, fôrça é ter em vista uma colaboração daquele fundamento do domínio eminente, de que fala RoDRIGo Otávio, como que dimanante "eficientemente da soberania, soma de direitos, às vezes imponderáveis, como que enfiteuse suprema que se traduz pelo exercício efetivo de uma atribuição de exceção". (11)

Quanto aos bens públicos de uso especial, o Código de Águas não cogita de águas com êsse caráter, não obstante poderem existir através do seu conceito específico.

\section{LIMITES DA DESAPROPRIAÇÃO}

O direito de desapropriação é atribuição do poder público, seja êle federal, estadual ou municipal.

No tocante à amplitude dêsse poder público e exercício de seu império: temos que considerar três graus diferentes:

$1^{\circ}$ ) o que se refere à União, cuja faculdade desapropriante pode ser exercida não só em relação aos bens particulares, como outrossim em relação aos bens públicos dos Estados e dos Municípios;

2. ${ }^{\circ}$ ) que se refere aos Estados, que se pode aplicar contra os bens particulares e os públicos do Município;

3. $\left.{ }^{\circ}\right)$ tinalmente, o que se refere aos Municípios, cuja execução só é pre vista em relação aos bens particulares.

(8) Clóvis, op. cit., vol. I, obs. ao art. 68.

(9) EURICO SODRÉ, $A$ desapropriação, pág. 22.

(10) Seabra Fagundes, Da desapropriação no Dir. Bras., n. ${ }^{\circ} 58$.

(11) Do Domínio da União e dos Estados, n. ${ }^{\circ} 10$, in fine. 
Não podem, portanto, os Estados desapropriar bens da União como não podem os Municípios desapropriar os mesmos bens e os dos Estados.

O princípio aí estabelecido dá vitalidade ao fundamento, que RodRigo OтÁvio lobrigou para a desapropriação, como sendo manifestação do dominio eminente em benefício do interêsse público, (12) teoria contra a qual se manifestou a crítica de Clóvis BEviláquA, que vê tal fundamento exclusivamente na preponderância do interêsse público sôbre o privado. (13)

No atinente às águas, o Código respectivo estabelece que as públicas de domínio comum e as patrimoniais dos Estados ou dos Municípios, bem como as águas comuns e as particulares, e respectivos álveos e margens, podem ser desapropriadas:

a) tôdas elas pela União;

b) as dos Municípios e as particulares, pelos Estados;

c) as particulares, pelos Municípios. (14)

Pode assim a União utilizar-se da faculdade constitucional erga omnes, em todo o território nacional; os Estados, cada qual dentro do seu território, sem que seja possível a um desapropriar bens situados no território de outro, embora necessários à integração de um seu serviço de necessidade ou utilidade pública; os Municípios, igualmente, só na sua circunscrição territorial em relação aos bens particulares.

Como a estabelecer uma restrição a essa faculdade, o Código de Águas determinou que a desapropriação ùnicamente se poderá verificar na hipótese de algum serviço público nêle classificado ou na legislação vigente. (15)

\section{MOTIVOS PARA A DESAPROPRIAÇÃO}

As expressões "necessidade ou utilidade pública" tiveram sua aplicação inicial em nosso direito na Lei n. ${ }^{\circ} 422$, de 9 de setembro de 1826 , já que a Constituição imperial nenhuma referência explícita fizera às condições nela contidas.

O propósito do legislador de então, estabelecendo os dois grupos, foi o de conferir, nas hipóteses de necessidade pública, ao Procurador da Fazenda Pública a verificação de sua exigência perante o Juiz do domicílio do proprietário, enquanto que, nos de utilidade pública, o reconhecimento do motivo deveria ser conseqüente de ato do Poder Legislativo, mediante requisição do mesmo Procurador. (16)

Tal distinção deixou de ter aprêço na última lei sôbre desapropriações pois que tôdas as hipóteses foram compreendidas dentro da "utilidade pú-

(12) RODRIGO OTÁvio, op. cit., n. ${ }^{\circ} 16, \mathrm{x}$.

(13) Cod. Civ. an., vol. 3. $\circ^{\circ}$ obs. 2 ao art. 590: "O fundamento da desapropriação é a preponderância do interêsse público sôbre o privado, quando os dois se acham em colisão". BARBALHO, na mesma compreensão, já definia a desapropriação: "E' uma limitação à propriedade privada, no interêsse superior da comunhão". (Com. à Const, Federal, art. 72, § 17, pág. 437).

(14) Código de Ásuas, art. 32.

(15) Código de Aguas, art. 33.

(16) Seabra Fagundes, op. cit., n. ${ }^{\circ}$ 12-A. 
blica", por ser o seu conceito mais amplo que o da "necessidade", tornando-se esta dispensável como justificativa da alienação forçada. (17)

Primitivamente ocorrera o inverso, de vez que a expressão "necessidade" fo1 a de que se utilizou no instituto, quando na Revolução Francesa, com a declaração dos direitos do homem, a Constituição de 14 de setembro de 1789 assim dispôs: "La proprieté est inviolable et sacrée. Nul ne peut être privé, si ce n'est lcrsque "La Necessité publique", légalement constatée, exige evidemment, et sous la condition d'une juste et préalable indemnité".

A dicotomia de expressões ressurgiu com o advento da Constituição Federal de 1946, que, como já vimos, ainda acresceu aos dois motiyos da "utilidade" e da "necessidade", o do "interêsse social".

O eximio comentador da lei vigente assim explica a inclusão feita pelo legislador constituinte: "Com base nêle (o interêsse social) terão lugar as expropriações que se façam para atender a plano de habitações populares ou de distribuição de terras, à monopolização de indústrias ou nacionalização de emprêsas, quando relacionadas com a política econômico-trabalhista do govêrno, etc." (18)

Qualquer dos motivos de desapropriação mencionados acima pode ser suscitado no campo do direito das águas, pois delas pode precisar o poder público, em decorrência de necessidade, utilidade ou interêsse social, contorme a hipótese.

\section{INDENIZAÇÃO PRÉVIA}

Uma das duas "condições impreteríveis" para a desapropriação, segundo o conceito de RUI BARBOSA, é a que vem expressa nos sucessivos textos constitucionais, como sendo "a indenização prévia", a que se executa pelo pagamento etetivo em moeda corrente (19) ou, em casos especiais, pelo depósito, também em moeda corrente, do valor real do objeto desapropriado. feito em juizo.

CLóvis BEVILÁqua enumera os seguintes casos permissíveis da consignaçáo, que é modalidade do pagamento previsto no artigo 972, do Código Civil :

$10^{\circ}$ ) se o proprietário recusa a indenização que foi arbitrada (Código Civil, art. 591, parágrafo único);

$\left.2 .^{\circ}\right)$ se o bem desapropriado estiver sujeito a garantia real, e neste caso, tar-se-á o depósito da garantia integral do credor;

$3 .^{\circ}$ ) se recair penhora sôbre o bem desapropriado, porque a penhora retira o bem da posse do devedor e o destina à venda judicial, para ser pago o exeqüente com o respectivo produto;

(17) Idem, idem, n.॰ 89 - Solidônio LeITE, Desapropriação, n. ${ }^{\circ} 15$, diz que não se pode fazer bem a distinção entre necessidade e utilidade pública, discriminando os serviços de uma e outra ordem.

(18) Seabra Fagundes, op. cit., n. $.^{\circ} 12-\mathrm{C}$.

(19) C. Maximitiano Com. à Const. Federal n..$^{\circ} 445$, in fine. Hoje o texto constitucional é explícito nesse sentido. 
4. $\left.{ }^{\circ}\right)$ não havendo transcrição do título, se a propriedade do prédio estiver contestada por ação real. (20)

Dilatando-se a esfera de permissibilidade do depósito na desapropriação, enquadram-se realmente nela tôdas as hipóteses previstas no artigo 973 do Código Civil.

RUI BARBOSA, porém, insurge-se contra a sua tolerância, em passagem cuja transcrição oferecemos: "Não é exato que quem deposita paga, porque, enquanto o preço da indenização permanece em depósito, o proprietário dêle está privado, sem poder aplicá-lo, nem dêle tirar proveito correspondente. Indenizar prèviamente e depositar, são atos que não se conciliam, antes se chocam, e repelem, quando se trata de desapropriação. Indenização prévia importa em pagamento anterior à realização de algum fato; depositar é dar a guardar o que tem de ser entregue mais tarde. A indenização prévia supõe um pagamento imediato, pronto, sem possibilidade de demora; o depósito presume tardança, espera de realização próxima ou remota de algum ato". (21)

Não parece proceder, em face do nosso direito positivo, a estupenda dialética do mestre.

Como já acentuamos, a consignação é modalidade de pagamento, cuja procedência se opera em determinados casos.

Êsses casos estão previstos na lei civil, e uma vez nêles haja incidência, o pagamento torna-se apto por via de depósito. Pairando qualquer dúvida acêrca de quem seja o proprietário do objeto desapropriado ou no intuito de respeitar direito de terceiros sôbre êles, o caminho indicado outro não pode ser senão o da consignação judicial. (22)

Nada obsta que expropriante e expropriado entrem em acôrdo para que a obrigação se indenize ou se extinga por transação entre ambos, aspecto outro por que se pode consumar o pagamento, como nada impede seja feito por uma dação ou por uma compensação.

\section{JUSTO VALOR EM DINHEIRO}

Ao lado da anterioridade da indenização, o vigente dispositivo constitucional relativo à desapropriação determina que a mesma se faça de um modo justo e em dinheiro.

Com o restabelecimento dessas condições, diz SEABRA FAGUndes que a Constituição "retirou à lei ordinária a faculdade de acertar critérios de aval1ação econômicamente insatisfatórios e prevenir dúvidas acaso suscetíveis sôbre a constitucionalidade do pagamento em valores outros que não o dinheiro." (23)

(20) Soluções Práticas do Direito, vol, 2, XX.

(21.) Rui Barbosa, op. e vol. cits., pág. 424.

(22) Clóvis, Espínola, LeVI CARNEIRo, SÁ Freire e outros pronunciaram-se a respeito da inadmissibilidade do depósito no caso de haver transcrição, o que - evidentemente nâo colide com o que ficou acima citado. Veja-se SolidônIo LEITE, op. cit., número 142-A.

(23) Seabra Fagundes, $O p$. cit., n. 14. 
Teve o inciso da Carta Magna o evidente irtuito de coibir a permissão contida no Decreto-lei n. ${ }^{\circ} 3.365$, de 21 de julho de 1941, art. 32, onde se permitia o pagamento "em títulos da dívida pública federal, de acôrdo com a cotação do dia anterior ao do depósito", (24) bem como tornar inaplicável o disposto no artigo $27, \S$ único do mesmo decreto-lei. (25)

\section{CASOS DE DESAPROPRIAÇÃO}

O Decreto-lei n. ${ }^{\circ} 3.365$, de 21 de julho de 1941 , no sế artigo $5 .^{\circ}$, sob a rubrica única de "casos de utilidade pública", enumera, em alíneas que vão da letra a à letra $p$, as diversas hipóteses que podem oferecer aso à desapropriação.

Dentro do lato pressuposto dessa última letra, que se refere aos demais casos previstos por leis especiais", já se enquadraria a faculdade despropriante no domínio das águas, constante do art. 32 do C. A., ainda que não houvesse de modo explicito feito referência na letra $f$ ao "aproveitamento das minas e das jazidas minerais, das águas e energia hidráulica".

O Código de Águas, em diversos dos seus artigos, faz alusão à utilidade pública; (20) e em outros refere-se expressamente à desapropriação, como acontece no caso de concessão, em que se permite ao concessionário, para a execução dòs trabalhos definidos no respectivo contrato, bem como para a exploração da concessão, "desapropriar nos prédios particulares e nas aıto. rizaçōes preexistentes, os bens, inclusive as águas particulares sôbre que verse a concessão e os direitos que forem necessários, de acôrdo com a lei que regula a desapropriação por utilidade pública ficando a seu cargo a liquidaçao e pagamento das indenizações". (27)

Irata-se de um caso de delegação de atribuições previstas na lei de desapropriaçöes, quando dispõe que "os concessionários de serviços públicos e os estabelecimentos de caráter público ou que exerçam funções delegadas dit poder público poderão promover desapropriações mediante autorização expressa, constante de lei ou contrato". (28)

Já a legislação pátria anterior cogitava da desapropriação das águas, isso em decorrência de renhido pleito judiciário travado em 1880 , de que participaram os mais eminentes juristas, entre êles LAFAyETTE, TeIXeIRA DE Freitas, Ribas, Amaro Cavalcanti e outros, dêle resultando o advento da Lej n." 3.396 , de 24 de novembro de 1888, "sôbre cujo art. 21 , n. ${ }^{\circ}$ II. se basearam a lei federal de 1903 e a maioria dos códigos estaduais de processos para fixar o critério da avaliação das águas". (29)

(24) "O pagamento do preco será feito em moeda corrente. Mas, havendo autorizacão prévia do Poder Legislativo, em cada caso, poderá efetuar-se em títulos da divida pública federal, admitidos em bôlsa, de acôrdo com a cotação do dia anterior ao do depósito".

(25) Se a propriedade estiver sujeita ao impôsto predial, o "quantum" da indenização nâo será inferior a 10 nem superior a 20 vezes o valor locativo, etc.".

(26) Para ilustracão do asserto, citamos os arts. 43 e 140.

(27) C. A. "art. 151, let. "b".

(28) Dec.-lei n. ${ }^{\circ} 3.365$, art. $3 .^{\circ}$.

(29) Eurico SOdrÉ, op. cit., pág. 56 - "Águas". 
$\mathrm{O}$ art. 37 e seus $\S \S$ do Regulamento baixado pelo Decreto n. ${ }^{0} 4.956$. de 1903, assim dispunha:

"O valor da indenização, nos casos da desapropriação de águas, será o que corresponder ao volume ou fôrça motora de que efetivamente utilisar-se o proprietário, ao tempo da desapropriação (Lei n. ${ }^{\circ} 3.396$, de 24 de novembro de 1888, art. 221, n. ${ }^{\circ}$ II).

$\S 10^{\circ} \mathrm{A}$ indenização não excederá à exigência do proprietário, nem será inferior:

a) à oferta prèviamente aprovada pelo Govêrno;

b) a $6 \%$ do valor da propriedade, constante de inventário, ou contrato de aquisição, revestido das formalidades legais, e na falta de inventário ou contrato, do valor que estimarem os arbitradores. (Lei n..$^{\circ} 3.396$, de 1888, art. 21, n. ${ }^{\circ} 11$ ).

$\S 2 .^{\circ}$ Quando o abastecimento exigir construções em terrenos próximos ou adjacentes aos mananciais, serão fixadas indenizações aos que para êsse fim forem desapropriados, segundo as regras do art. 31. (Lei n. ${ }^{\circ} 3.396$, de 1888, art. 22).

$\S 3 .^{\circ}$ Possuindo o proprietário estabelecimento que fique prejudicado com a desapropriação, por não permitir o interêsse público, que, na forma do parágrafo seguinte, the seja fornecida quantidade de água suficiente para a respectiva exploração, será também desapropriado o mesmo estabelecimento, regulando-se a indenização pelo disposto no mencionado art. 31 . (Lei n. ${ }^{\circ} 339$, de 1888 , art. 23).

§ $4 .^{\circ}$ Além da indenização, é garantida ao proprietário a quantidade de água necessária ao consumo doméstico, fazendo-se, para êsse fim as convenientes derivações. (Lei n. ${ }^{\circ} 3.396$, de 1888, art. 24)".

T-Vo atinente à desapropriação das terras foreiras da União, entre as quais as constantes de terrenos de marinha, incluíclos no estudo do Direito das Águas, (30) o Govêrno discricionário baixou o Decreto n. ${ }^{\circ} 24.606$, de 6 de julho de 1934 , onde são regulados diferentes processos para a determinação das indenizações, critérios hoje derrogados pelo princípio constitucional, que manda seja ōsservado o "justo valor" (31) como critério primacial.

\section{UTILIDADE PÚBLICA}

Conquanto o Decreto-lei n. ${ }^{\circ} 3.365$, de 21-6-1941, só se referia a desapropriação por utilidade pública, (32) a vigente Constituição Federal continua a insistir no uso da expressão "por necessidade ou utilidade núbliç", e ainda the acrescenta o "interêsse social" como sendo compreensivo de modalidade à parte.

(30) C. A., arts. 13 e 30.

(31) Seabra Fagundes, n. ${ }^{\circ}$ 14-D.

(32) Artigos 1 e 5 . 
O legislador ordinário entendeu que a simples utilidade pública era motivo para a expropriação, e assim, dentro do seu conceito, compreendeu que estarıa também a necessidade pública, de mais exigente satisfação.

Não obstante no fundo tenham as mesmas características e gerem os mesmos processos com idênticas conseqüências, são realmente hipóteses distintas, que, intercorrendo na órbita do direito privado, por limitarem a proprie. dade, toram assinaladas e desdobradas no art. 590 do Código Civil.

Aí vêm considerados como sendo casos de necessidade pública:

a) a defesa do território;

b) a segurança pública;

c) os socorros públicos nos casos de calamidade; e

d) a salubridade pública.

E como casos de utilidade pública:

a) a fundação de povoações e de estabelecimentos de assistência, edu.cação ou instrução pública;

b) a abertura, alargamento ou prolongamento de suas ruas, praças, canars, estradas de ferro e em geral, quaisquer vias públicas;

c) a construção de obras, ou estabelecimentos destinados ao bem gerai de uma localıdade, sua decoração e higiene;

d) a exploração de minas.

Bem razão tinha, entretanto, o egrégio SÁ PEREIRA, quando assinalou:

"Por mais casuística que a do legislador ordinário tenha sido, a tese constitucional talvez não se tenha esgotado e teremos então de passar além do Código para ficar dentro da Constituição". (33)

Daí por que, com tôda procedência disse eminente constitucionalista pátrio: Desapropria-se tudo que pode servir para efetuar uma obra de utilidade publica: água corrente ou em cachoeira, terrenos, casas, pedreiras, privilégios, concessões". (34)

O Decreto-lei n. 3.365 , citado, enumera nas letras a a $p$ do artigo 5 , varios casos, que enquadra entre os de utilidade pública, os quais, todavia, anda não esgotam o princípio constitucional.

Entre êsses casos, tem particular interêsse, no estudo que está sendic teito, o constante da letra $f$ "o aproveitamento industrial das minas e des Jazidias minerais, das áǵuas e da energia elétrica".

O Decreto-lei n. ${ }^{\circ} 1.283$, de 18-5-1939, anterior ao atual estatuto das desapropriações de 1941, tinha neste particular um dispositivo categórico, que era o do seu artigo $2 .^{\circ}$ : "Nos processos de desapropriação, não compete ao Poder Judiciário averiguar e decidir se se verificam ou não os casos de necessıdade ou utilidade pública, cuja enumeração na lei é apenas exemplitrcatrva”.

(33) SÁ Pereira, Man. do Cod. Civ., vol. VIII, n. 126.

(34) C. Maximiliano, Com. à Constit., n. ${ }^{\circ} 445$. 